\title{
PRÁTICAS INCLUSIVAS DE ALUNOS COM TEA: PRINCIPAIS DIFICULDADES NA VOZ DO PROFESSOR E MEDIADOR
}

\author{
INCLUSIVE PRACTICES OF STUDENTS WITH ASD: MAIN \\ DIFFICULTIES IN THE TEACHER'S VOICE AND MEDIATOR
}

\author{
PRÁCTICAS INCLUSIVAS DE ALUMNOS CON TEA: PRINCIPALES \\ DIFICULTADES EN LA VOZ DEL PROFESOR Y MEDIADOR
}

\author{
Célia de Jesus Silva MAGALHÃES ${ }^{1}$ \\ Cloves Santos de MORAES ${ }^{2}$ \\ Jaíze Griffith Magalhães CRUZ ${ }^{3}$ \\ Lígia Maria Tavares SAMPAIO ${ }^{4}$
}

RESUMO: As práticas inclusivas para alunos com Transtorno do Espectro Autista TEA são importantes no dia-a-dia da sala de aula, tendo em vista a prioridade na aprendizagem, comunicação e interação dos alunos, e não apenas à presença física. Porém, as dificuldades do professor e mediador com relação às práticas pedagógicas se apresentam como barreiras do processo nesses espaços de aprendizagem sem uma compreensão didática dos docentes que carecem de estudos. Partindo dessa problemática, esta pesquisa tem como objetivos investigar as dificuldades enfrentadas pelos professores e mediadores em sala de aula e identificar as práticas e intervenções pedagógicas mais eficientes direcionadas para a aprendizagem de crianças autistas. A pesquisa bibliográfica nos ajudou no diálogo com a legislação básica LDB 9.294/96, Lei 12.764/2012 e com os relatórios das observações das aulas, como proposta de perceber quais as práticas com melhores resultados e as dificuldades. Utilizamos a entrevista como instrumento de coleta de dados, com dois professores: um mediador e um coordenador pedagógico. Os sujeitos entrevistados revelaram nas suas falas que apesar de utilizarem os métodos ABA (análise Aplicada do Comportamento) e PECS (Sistema de Comunicação pela troca de figuras) como práticas pedagógicas eficientes, ainda sentem muitas dificuldades com relação à adaptação de atividades (exercícios, trabalhos individuais e coletivos) e explicação dos conteúdos programáticos curriculares, como também a comunicação com os alunos autistas e a falta de formações continuadas para a efetivação das práticas inclusivas na escola, sendo esta última decisiva para a busca de conhecimentos capazes de provocar novas discussões e novas possibilidades didáticas.

PALAVRAS-CHAVE: Práticas inclusivas. Professor. Mediador. TEA.

${ }^{1}$ Universidade Regional do Cariri (URCA) - CE - Brasil. Professor substituto. E-mail: celia.magalhaes@urca.br.

${ }^{2}$ Universidade Regional do Cariri (URCA) - CE - Brasil. Bolsista PIBIC/URCA/FUNCAP. E-mail: clovessantos0@gmail.com.

${ }^{3}$ Faculdade Leão Sampaio, CE - Brasil. Aluna do Curso de Psicologia. da Faculdade Leão. Membro da AMA - Cariri. E-mail: jaizinha-mv@ @otmail.com.

${ }^{4}$ Universidade Regional do Cariri (URCA) - CE - Brasil. Graduanda em Letras. E-mail: lctavaresleite@hotmail.com. 
RESUMEN: Las prácticas inclusivas para alumnos con trastorno del espectro autista TEA son importantes en el día a día del aula, teniendo en cuenta la prioridad en el aprendizaje, comunicación e interacción de los alumnos, y no sólo a la presencia física. Sin embargo, las dificultades del profesor y mediador con relación a las prácticas pedagógicas se presentan como barreras del proceso en esos espacios de aprendizaje sin una comprensión didáctica de los docentes y carecen de estudios. A partir de esta problemática, esta investigación tiene como objetivos investigar las dificultades enfrentadas por los profesores y mediadores en el aula e identificar las prácticas e intervenciones pedagógicas más eficientes dirigidas al aprendizaje de niños autistas. La investigación bibliográfica nos ayudó en el diálogo con la legislación básica LDB 9.294 / 96, Ley 12.764 / 2012 y con los informes de las observaciones de las clases, como propuesta de percibir cuáles son las prácticas con mejores resultados y sus dificultades. Utilizamos la entrevista como instrumento de recolección de datos, con dos profesores, un mediador y un coordinador pedagógico. Los sujetos entrevistados revelaron en sus palabras que a pesar de utilizar los métodos ABA (Análisis Aplicado del Comportamiento) y PECS (Sistema de Comunicación por el intercambio de figuras) como prácticas pedagógicas eficientes, todavía sienten muchas dificultades con relación a la adaptación de actividades (ejercicios, trabajos individuales y colectivos) y explicación de los contenidos programáticos curriculares, así como la comunicación con los alumnos autistas y la falta de formaciones continuadas para la efectividad de las prácticas inclusivas en la escuela, siendo esta última decisiva para la búsqueda de conocimientos capaces de provocar nuevas discusiones y nuevas posibilidades didácticas.

PALABRAS CLAVE: Prácticas inclusivas. Profesor. Mediador. TEA.

ABSTRACT: Inclusive practices for students with ASD - Autistic Spectrum Disorderare important in the daily life of the classroom, given the priority of students' learning, communication, and interaction, not just physical presence. However, the difficulties of the teacher and mediator regarding pedagogical practices present themselves as barriers to the process in these learning spaces without a didactic understanding of the teachers and it lack studies. Based on this problem, this research aims to investigate the difficulties faced by teachers and mediators in the classroom and to identify the most efficient pedagogical practices and interventions aimed at the learning process of autistic children. The bibliographic research helped us in the dialogue with the basic legislation LDB 9.294 / 96, Law 12.764 / 2012 and with the reports of the observations of the classrooms, as a proposal to perceive which practices have better results and their difficulties. We used interviews as a data collection instrument, with two teachers, a mediator and a pedagogical coordinator. The subjects interviewed revealed that despite using ABA (Applied Behavior Analysis) and PECS (Picture Exchange Communication System) as efficient pedagogical practices, they still feel many difficulties regarding the adaptation of activities (exercises, individual and collective work) and explanation of the syllabus, as well as the communication with the autistic students and the lack of continuous formations for the accomplishment of the inclusive practices in the school, being the latter decisive for the search of knowledge capable of provoking new discussions and new possibilities.

KEYWORDS: Inclusive practices. Teacher. Mediator. ASD. 


\section{Introdução}

Os estudos sobre inclusão e práticas inclusivas são temas debatidos nas Universidades, eventos, Instituições escolares e sociais, buscando respostas e soluções para as barreiras que impedem o processo de acontecer e os resultados práticos se tornarem visíveis. Sendo esse um tema polêmico entre os educadores, as opiniões acabam sendo divididas, visto que, muitos professores sem ter conhecimento do assunto se colocam contra o processo inclusivo na escola, por afirmarem que não estão preparados para essa ação pedagógica.

E, quando tratamos de Transtorno do Espectro Autista (TEA) e o processo inclusivo, a escola apresenta várias dificuldades, justificando o desconhecimento dessa deficiência. O setor pedagógico se mostra despreparado para realizar a inclusão dessa criança, já que esse processo exige uma gama de conhecimentos específicos, começando com os mais simples conceitos e as práticas na sala de aula, incluindo estudo dos conteúdos, adaptação de atividades de sala e de casa, trabalhos individuais e coletivos e a rotina do aluno autista. Os problemas enfrentados pela família do aluno com TEA, que vão desde a falta de informação nas instituições escolares até a falta de formação adequada de professores, que na sua formação inicial não tiveram nenhum conteúdo curricular desse tema, são obstáculos recorrentes.

Os estudos sobre TEA começaram na década 1940 e atualmente se intensificaram mostrando que na maioria dos casos, as crianças com TEA não aprendem de forma satisfatória. Isso ocorre porque as escolas utilizam quase exclusivamente os métodos tradicionais de ensino, que não correspondem às expectativas desse grupo discente, tendo em vista que as maneiras de aprenderem não são e nem podem ser iguais às das outras crianças. É desse ponto que nasceu a nossa preocupação com os desafios que o professor precisa vencer na sala de aula e as intervenções pedagógicas necessárias nesse espaço.

O interesse pelo tema vem justamente de conhecer as práticas pedagógicas inclusivas do professor em relação aos alunos com TEA e as dificuldades enfrentadas por ele e o mediador ${ }^{5}$ em sala de aula, identificando o modelo dessa inclusão escolar,

5 O mediador é identificado como àquele profissional que auxilia o professor no processo de aprendizagem do aluno, principalmente com relação à aplicação e adaptação de atividades e avaliações, porém nem todos os mediadores tem formação de curta duração na área de inclusão. Isso poderá impactar de forma negativa na aprendizagem e no trabalho pedagógico. 
frente aos desafios e o entendimento da legislação que orienta o processo inclusivo na sociedade.

Apesar da Declaração de Salamanca (1994), da LDB 9.394/96, da Lei 12.764/12 (Lei Berenice Piana), dentre outros documentos que amparam legalmente os direitos das pessoas com necessidades educacionais especiais, (especificamente das pessoas com TEA), ainda há o desrespeito e/ou desconhecimento sobre esses direitos. Sabemos, no entanto que as escolas nem sempre encaram a inclusão como ação fortalecedora dos direitos humanos e educacionais. $\mathrm{O}$ objetivo deste trabalho é investigar quais as dificuldades enfrentadas pelos professores e mediadores em sala de aula, bem como identificar as práticas e intervenções pedagógicas mais eficazes, direcionadas para a aprendizagem das crianças autistas, levando em consideração as limitações na formação inicial e continuada do professor.

Partindo de estudos sobre a lei que orienta a inclusão de pessoas com TEA, Lei 12.764/12, o Decreto 8.368/2014 ${ }^{6}$, que regulamenta essa Lei, e a pesquisa bibliográfica, utilizando Cunha (2013), Faccion (2008), Rodrigues e Spencer (2010),Vieira (2013), dentre outros, exporemos o nosso entendimento, realizando uma ligação entre as teorias e as falas dos professores e mediadores e nossas observações na sala de aula, para complementar a nossa pesquisa.

Este trabalho está em andamento, utilizamos a abordagem qualitativa, com a realização de observações em sala de aula e elaboração de relatórios, bem como aplicação de um instrumento de coleta de dados (entrevista semiestruturada), em uma escola privada da cidade de Missão Velha, à 04 (quatro) profissionais; dentre eles 2 (dois) professores, 01 (um) coordenador pedagógico e 01 (um) mediador. O objetivo da entrevista é ouvir desses profissionais as principais dificuldades no processo de ensino e aprendizagem de alunos com TEA. A escolha da escola se deu ao identificarmos que alunos participantes do Projeto de Extensão de Alfabetização de alunos com TEA, desenvolvido pela AMA-Cariri ${ }^{7}$, estudavam nesta escola. Acreditamos que esses profissionais poderão nos trazer informações esclarecedoras acerca dessas dificuldades e desafios da escola e da sala de aula frente às intervenções e práticas pedagógicas.

${ }^{6}$ O DECRETO $n^{\circ} 8.368$, de 2 de dezembro de 2014, regulamenta a Lei Berenice Piana, 12.764/ 2012 que institui a Política Nacional de Proteção dos Direitos da Pessoa com TEA.

${ }^{7}$ AMA - Cariri é a Associação de Pais, Amigos e Profissionais dos Autistas do Cariri, criada no ano de 2015, na cidade de Missão Velha -CE, por iniciativa dos pais de uma criança autista, um grupo de familiares, amigos e professores. 


\section{TEA: legislação e histórico.}

TEA é tema é atualmente estudado por pesquisadores da área de educação, saúde e áreas afins, em virtude de demandas sociais com o surgimento de muitos diagnósticos de crianças e jovens com TEA. Ao longo dos anos 1990, os estudiosos voltaram sua atenção para pessoas com deficiência. É durante essa década que diversos organismos passaram a criar diretrizes e leis, voltadas para pessoas com TEA nas escolas e na sociedade. Como exemplo, podemos citar, a nível internacional, a Declaração de Salamanca $(1994)^{8}$, no Brasil temos a LDB - Lei de Diretrizes e Bases da Educação Nacional - 9.394/96, que em seu artigo $2^{\circ}$ enfatiza a educação como direitos de todos, dever do estado e da família. Os artigos 58 e 59 da referida Lei, dão ênfase maior à questão da inclusão escolar, generalizando (sem especificar os tipos de deficiência), os indivíduos com necessidades educacionais especiais (NEE), e seus direitos; como currículo adequado, professores com formação adequada, educação para o trabalho e acesso aos programas sociais.

Ao trazer essa discussão com a legislação sobre a inclusão, vamos observar algumas especificidades legais, como a Lei $12.764 / 12^{9}$ - que vem instituir a Política de Proteção dos Direitos da Pessoas do Espectro Autista, que em sua essência, vem instituir a política pública dos direitos da pessoa com TEA, explicitando seus direitos e esclarecendo que o autismo é uma deficiência.

Vejamos os direitos da pessoa com TEA:

Art. $3^{\circ}$ São direitos da pessoa com transtorno do espectro autista: I - à vida digna, a integridade física e moral, o livre desenvolvimento da personalidade, a segurança e o lazer;

II - à proteção contra qualquer forma de abuso e exploração;

III - o acesso à ações e serviços de saúde, com vistas à atenção integral às suas necessidades de saúde, incluindo:

a) o diagnóstico precoce, ainda que não definitivo;

b) o atendimento multiprofissional;

c) à nutrição adequada e a terapia nutricional;

d) os medicamentos;

e) informações que auxiliem no diagnóstico e no tratamento;

IV - o acesso:

${ }^{8}$ A Declaração de Salamanca é um Documento que tem seu marco espacial na Espanha em 1994, com o objetivo de apontar para a criação efetiva de políticas públicas voltadas à inclusão urgente de crianças e jovens que apresentam necessidades educacionais especiais. Ver documento completo http://portal.mec.gov.br/seesp/arquivos/pdf/salamanca.pdf

${ }^{9}$ Ver Lei Berenice Piana - 12.764/12 - Institui a política nacional de proteção dos direitos da pessoa com Transtorno do Espectro Autista e altera o $\S 3^{\circ}$ do Art.. 98 da Lei 8.112 de 11 de dezembro de 1990. Ver documento na íntegra. Disponível em: <http://www.planalto.gov.br/ccivil_03/_ato20112014/2012/lei/112764.htm>. 
a) à educação e ao ensino profissionalizante;

b) à moradia, inclusive à residência protegida;

c) ao mercado de trabalho;

d) à previdência social e à assistência social.

Parágrafo único. Em casos de comprovada necessidade, a pessoa com transtorno do espectro autista incluída nas classes comuns de ensino regular, nos termos do inciso IV do art. 2º, terá direito a acompanhante especializado. (BRASIL, 2012)

$\mathrm{Na}$ vida prática, as famílias que tem no seu núcleo familiar pessoas com TEA, sentem dificuldades no cumprimento desse artigo, pois as políticas públicas não dispõem dos mecanismos necessários para o cumprimento das exigências legais.

Segundo Rodrigues e Spencer (2010, p. 14), autismo

[...] é um distúrbio do desenvolvimento. [...] A pessoa autista apresenta dificuldades de realizar mudanças em sua rotina diária, há, no entanto, a capacidade de refazer ações por imitação, de início, posteriormente por transformação, quando é trabalhado o espaço, casualidade e generalidades em suas ações.

Os estudos de Kanner (psiquiatra), sobre autismo, em 1943 quando fez um trabalho com um grupo de 11 crianças que apresentavam características clínicas específicas, diferente das já estudadas pela literatura da época, apontando para dificuldades de comunicação, relacionamento, contatos afetivos e às vezes comportamento agressivo (BELISÁRIO FILHO; CUNHA, 2010; MACÊDO, 2015), são considerados importantes para as pesquisas nessa área.

$\mathrm{Na}$ mesma década, o médico austríaco Hans Asperger, que publicou suas observações em 1944, com o título A psicopatia autista na infância, caracterizou o autismo como deficiência (grifos meus). Esses estudos só foram conhecidos a partir da década de 80. Asperge descreveu as relações sociais e afetivas, comunicação e linguagem pensamento, comportamento e atitudes.

As observações de Asperger mostram que o grupo por ele observado tinha inteligência dentro da normalidade e capacidade de se comunicar oralmente. Daí a assertiva de que há aspectos evidentes de semelhança entre Leo kanner e Asperger nos estudos sobre comunicação e linguagem, em que ressaltam alteração das propriedades da fala, referente à ritmo e entonação, constituindo-se em uma fala com sons estranhos.

No período de 1950 e 1960, o autismo foi caracterizado como transtorno. Na década de 1970, Michael Rutter descreve uma sintomatologia mais precisa, utilizando 
na terceira versão do Manual Diagnóstico e Estatístico de Doenças Mentais (DSM-III), publicado pela APA - Associação Americana de Psiquiatria (1987), permanece ainda a nomenclatura, Transtorno Global de Desenvolvimento (TGD); Os TGDs englobavam vários transtornos: O autismo, Síndrome de Asperger, (Os TGDs não especificados), TD - Transtorno Desintegrativo e a Síndrome de Rett. Uma característica comum entre todos é o comprometimento na área social e na comunicação (BEZ apud MACÊDO, 2015).

O ano de 1994 foi um marco importante para a publicação do DSM -IV com novos critérios para o diagnóstico do Autismo. E em 2013, foi publicada a nova versão do (DSM), DSM-V, e o Autismo passou a ser denominado Transtorno do Espectro Autista - TEA ${ }^{10}$ (grifos meus). Segundo Macêdo (2015), "sua sintomatologia, manifestada em diferentes níveis de gravidade é caracterizada por alteração da comunicação social e presença de comportamentos repetitivos e estereotipados" (MACEDO, 2015, p. 26). As causas do autismo ainda são desconhecidas e nos últimos anos os estudos que possibilitaram os diagnósticos trouxeram um aumento do número de casos e, somando-se a isso, podemos confirmar que as famílias, buscando integrá-los no convívio social deles, matricularam-nos em escolas de ensino regular e procuraram a ajuda em outras instâncias do poder público.

Atualmente, permanecem as questões de dificuldades ligadas ao cognitivo, linguagem e as relacionadas ao déficit de compreensão na codificação e decodificação das palavras e ao que chamamos "ecolalia ou mutismo".

De forma geral, o autismo traz diversas outras características, tendo maior destaque àquelas ligadas ao comportamento social, quando é constatada a incapacidade de uma criança autista desenvolver relações pessoais porque o isolamento social prevalece em detrimento à sua interação com os outros grupos sociais (Rodrigues; Spencer, 2010). A literatura cita gestos repetitivos, olhar fixo em algum objeto ou no próprio corpo, algumas manias, como acender e apagar lâmpadas, movimentos repetitivos com os pés, braços ou cabeça, provocam estranhamentos de pessoas que desconhecem esse transtorno (CUNHA, 2013; PEREIRA, 2015).

Além de todas essas características, as crianças autistas apresentam insônia e consequentemente uma agitação comportamental e problemas relacionados ao aparelho digestivos, como diarreias sem indicação infecciosa.

${ }^{10}$ O DSM-V. Disponível em: <http://www.dsm5.org/>. Acesso em: 28 ago. 2017. 
Esse delineamento é uma forma de compreendermos as limitações da criança com TEA, nos colocando como aprendizes no mundo autista, para que possamos contribuir de forma à melhorar a vida social, familiar e educativa dos acometidos por essa deficiência, possibilitando uma inclusão digna.

\section{As práticas inclusivas acontecem na escola?}

A proposta pedagógica da escola traz o retrato do que acontece no processo inclusivo nesse espaço. É através da análise da proposta pedagógica que podemos observar se a instituição trabalha com a inclusão nos seus projetos. A pergunta é muito presente na comunidade: as práticas inclusivas acontecem na escola? Como acontecem? Quais as dificuldades do professor e do mediador? Sabendo que a inclusão é o caminho para a garantia do direito à educação de todos, tendo como prerrogativas os direitos humanos e uma postura profissional voltada para proposições do direito de aprender, devemos ser defensores legítimos do processo inclusivo.

A escola, a partir da organização sistemática divide os alunos em "normais e deficientes", o ensino em regular e especial, os professores em profissionais especialistas. Isso traz uma visão estanque, resultado do ideário moderno, que ignora o lado mais humano e destaca o que é técnico; romper o tradicional e aderir ao novo, não é fácil, reconhecer a inclusão escolar e social, na interface das contradições excludentes, é vislumbrar uma sociedade com novas possibilidades de uma educação para todos e um fazer pedagógico que requer estudos, reflexões, adesão e vontade de optar por uma prática menos excludente.

O Documento Subsidiário da política de inclusão (2005, p. 25) reforça que: "a inclusão de crianças com necessidades educacionais especiais produz impasses no cotidiano escolar que exigem um constante repensar das práticas pedagógicas é importante a análise de alguns aspectos do contexto atual da inclusão no país”.

A formação continuada de professores é muito importante para a sua atualização pedagógica e se constitui hoje uma das maiores dificuldades para a prática docente com os alunos com necessidades educacionais especiais, pois a falta da formação continuada deixa uma lacuna na atualização de novos conhecimentos pedagógicos (PAULON; FREITAS; PINHO, 2005). 
Essa formação deve ser contínua, tendo em vista a atualização e a participação no processo inclusivo de outros profissionais, ou seja, uma equipe multidisciplinar ${ }^{11}$ que favoreça um processo mais completo, capaz de compreender de forma coletiva os motivos que levam muitas crianças e adolescentes à não conseguirem ter a escola como um lócus de aprendizagem, igualdade, amizade e respeito.

Para que o professor possa desenvolver com êxito as atividades em sala de aula, deverá percorrer três etapas nesse trabalho: observação, avaliação e mediação (CUNHA, 2013).

A observação: parte da premissa de conhecer a criança e/ou o adolescente. Isso denota uma tarefa do professor quase natural, comungando com as ideias do autor citado, na maioria das vezes é o professor o primeiro a perceber algum sinal diferente no aluno(a), seja pelo comportamento, seja por reação que chame a atenção ou por silêncio e inquietude fora da normalidade; diante de alguns fatos ou momentos de interação em sala de aula. Essa observação "faz do professor um pesquisador, pois ele pode registrar o que vê”, sem o olhar preconceituoso (IBID, p. 56).

Estamos desenvolvendo um Projeto de Alfabetização na AMA - Cariri, destinado a alunos com TEA, que ainda não estão alfabetizados. Esse projeto nos aproximou de algumas reflexões acerca de práticas pedagógicas do professor, com o objetivo de contribuir para o êxito da aprendizagem desses alunos, levando em conta a observação, avaliação e mediação (CUNHA, 2013)

$\mathrm{Na}$ etapa de avaliação: avaliar para retomar um planejamento significa saber dar continuidade ao que se propõe. Nossa percepção diante da avaliação está ligada à atribuição de valor e nesse caso isso é o que menos interessa, porque o que mais importa é ter o desempenho discente de forma positiva diante do trabalho pedagógico, sendo mais uma ação mediadora. O professor precisa se avaliar e avaliar os instrumentos que têm disponíveis (entrevista com os pais e os recursos pedagógicos), nas práticas avaliativas de alunos com TEA, que ajudam ao professor na tomada de decisões. Cunha (2013), aponta três sugestões para essas avaliações: jogos, desenhos e pareamentos para, a partir disso, o professor definir o seu projeto pedagógico com o aluno com TEA. Essas atividades poderão ser elaboradas buscando-se modelos e sugestões conforme o que for obtido na atividade diagnóstica pedagógica com ajuda da equipe multidisciplinar e a anamnese com os pais.

11 Essa equipe multidisciplinar tem um papel importante, incluindo psicólogos, fonoaudiólogos, pedagogos e terapeutas ocupacionais. 
A auto avaliação também é importante, porque implica na percepção do docente sobre quais os seus pontos fracos e fortes para a retomada de novos caminhos mais eficazes. Há outros instrumentais para proceder à avaliação, além do já sugeridos pelo currículo. Cunha (2013, p. 60), “Jogos: possibilitar uma leitura de aspectos relacionados à função simbólica; Desenhos: verificar maturidade emocional, aspectos motores e cognitivos por meio de produção gráfica; Pareamentos: investigar esquemas lógicos de raciocínios [...]". Partindo desse processo avaliativo o professor poderá tirar suas conclusões sobre as maiores dificuldades do aluno, interesse ou habilidades.

A terceira e última etapa, a mediação: é o processo que acontece entre um estímulo e uma resposta. É um elo que possibilita uma intervenção, sendo consequência do que foi observado e do processo avaliativo. "Um dos principais escopos da mediação é criar vínculos entre o educando, o professor e o espaço escolar (IBID, p. 62)”.

Sobre a formação do professor, afirmamos que, infelizmente, a maioria das escolas no Brasil não tem no seu quadro docente professores com formação adequada para entender a inclusão e muito menos para atuar de forma pedagógica e correta na sala de aula com alunos com (TEA).

\section{Algumas Intervenções: ABA, PECS}

O planejamento de ações e estratégias requer conhecimento, por isso defendemos que o professor precisa ter ao menos um conhecimento básico para ser gestor de uma sala com aluno (a) autista ou um mediador de aprendizagem. Esse conhecimento, caso não tenha sido adquirido em sua formação inicial, poderá ser obtido através de cursos de curta duração sobre o tema e leituras ou grupos de estudos; e a partir desse ponto, o professor se torna hábil para traçar suas estratégias de ensino e aprendizagem.

Podemos assinalar algumas dicas pedagógicas importantes: atividades não muito longas, pedir orientação de quem já tem experiência e prestar atenção nas tarefas não concluídas. Vamos focalizar em alguns pontos voltados para a comunicação:

Levando adiante os questionamentos e a busca das respostas: "Como é o seu repertório verbal? Como estabelece a comunicação? [...] Utiliza de gestos em lugar de palavras? As sugestões do autor fazem um elo de ligação da comunicação: afeto, clareza e objetivo (CUNHA, 2013, p. 67). 
Vamos citar algumas intervenções pedagógicas como ABA - (Applied Behavior Analysis, no original, ou Análise Aplicada do Comportamento) e PECS- (PICTURE Exchange Communication System, que significa (Sistema de Comunicação pela troca de figuras), destinadas à alunos com TEA, como recurso para aprendizagem. O método ABA, é uma técnica proveniente do campo científico do behaviorismo, as pesquisas nessa abordagem têm crescido em todo o mundo e teve grandes pesquisadores como Skinner e Watson. O objetivo desse método é observar, analisar e explicar a associação entre o ambiente, o comportamento humano e a aprendizagem, visando a mudança de comportamentos específicos do aluno(a). O método visa ensinar ao autista habilidades que ele ainda não possui por meio de etapas cuidadosamente registradas. Cada habilidade é apresentada associando-se à uma indicação ou instrução. Em alguns casos é dado um apoio para a obtenção das respostas, porém essa ajuda inicial deverá ser retirada logo que possível, para possibilitar a autonomia da criança (CUNHA, 2013).

Nessa abordagem se torna importante a repetição e o registro exaustivo de todas as tentativas, bem como os resultados alcançados por meio de reforço e repetição. É um tipo de condicionamento que tem auxiliado muitos profissionais. Vários estudos comprovam avanços na aprendizagem e no desenvolvimento de habilidades das pessoas com TEA.

PECS - (Picture Exchange Communication System), foi desenvolvido em 1985 por Andy Bondy (psicólogo) e Lori Frost (fonoaudióloga). O protocolo baseia-se na investigação e na prática dos princípios da ABA (Vieira, 2013). O objetivo principal é ensinar a pessoa que apresenta déficit no repertório verbal e que apresentam dificuldades na fala e na comunicação.

Podemos recorrer também ao uso da tecnologia para a aprendizagem do aluno com TEA, como relata PEREIRA et al. (2015), sobre a TA Tecnologia Assistiva ${ }^{12}$, no trabalho "transtorno do Espectro Autista: definição, características e atendimento educacional."

O registro da ABA e PECS, demonstram que há algumas práticas de intervenções que podem auxiliar o professor, dentre tantos outros que vão potencializando as práticas pedagógicas na escola e na sala de aula, além de atividades adaptadas e outras sugestões que poderão ser organizadas pelo professor e pelo mediador para que o aluno com TEA sinta-se parte do processo escolar e a família perceba que é possível incluí-lo como sujeito ativo no ambiente escolar.

12 BERSCH, Rita. Sugestão de aprofundamento de TA. Porto Alegre-RS, 2013. Disponível em: $<$ http://www.assistiva.com.br/Introducao_Tecnologia_Assistiva.pdf $>$. 


\section{Das observações: as principais dificuldades do professor e do mediador}

Tivemos a oportunidade de realizar quatro observações no mês de maio e junho de 2017 em uma sala de aula de uma escola X da cidade de Missão Velha -CE, em que havia um aluno com TEA, utilizaremos a letra A para o aluno (está cursando do $3^{\circ}$ ano do ensino fundamental), P1 para uma professora, P2 para a outra professora, a letra M para a mediadora e CP para o coordenador pedagógico ${ }^{13}$, que responderam as entrevistas, com o objetivo de respeitar o anonimato. Porém, esclarecemos que todos assinaram os termos de consentimento, inclusive a mãe do aluno com TEA e a direção da escola que autorizou essas observações.

As entrevistas foram realizadas inicialmente com duas professoras, uma mediadora e uma coordenadora pedagógica, entre os meses de junho e julho de 2017.

A escola campo deste estudo realmente realizou algumas mudanças na sua rotina e nas suas práticas, mas algumas vezes acontecerem embates com as famílias dos alunos com TEA com relação ao processo pedagógico e a rotina desses alunos.

Houve boa receptividade para a realização deste trabalho tanto por parte da direção, como por parte dos coordenadores e professores, apesar de saber que a nossa presença às vezes poderia incomodar.

Nas observações realizadas na sala que tem um aluno com TEA, foi possível perceber que as professoras se dirigiam pouco ao aluno A, na hora de explicações pertinentes aos conteúdos e atividades. O aluno ficava em contato maior com a mediadora M e não havia interação entre o aluno A e as professoras P1 e P2 da sala de forma satisfatória para o processo normal de aprendizagem. Por alguns momentos o aluno A se agitou e depois se acalmou. A mediadora relatou que às vezes isso acontecia quando ele não queria realizar a tarefa ou algo que contrariasse a sua vontade. Havia na sala um quadro escrito: "Rotina de A", mas não havia nada escrito da rotina. Durante os outros dias foi colocada a rotina no quadro. Eu percebi que a prática pedagógica das professoras está voltada para os alunos da sala, inclusive as explicações para resolução das tarefas. Considerei positivo o relacionamento dos alunos da sala, com relação ao aluno $\mathrm{A}$, pois não reclamavam e nem questionavam a situação diferente do aluno $\mathrm{A}$. Com relação ao trato pedagógico da mediadora $\mathrm{M}$ com o aluno $\mathrm{A}$, nos momentos em

${ }^{13}$ Quanto à formação das profissionais envolvidas nesse estudo: As professoras P1 e P2 tem Licenciatura em Letras com especialização na área. A CP é pedagoga e tem especialização na área de Letras. A mediadora está cursando pedagogia. As professoras, mediadora e coordenadora pedagógica têm cursos de curta duração. A escola tem proporcionado momentos de discussão sobre Inclusão e cursos de curta duração. Todos têm conhecimento da legislação sobre inclusão.

RPGE- Revista on line de Política e Gestão Educacional, Araraquara, v.21, n. esp.2, p. 1031-1047, nov. 2017. $\quad$ ISSN: 1519-9029 
que o aluno A se agitou sem motivação aparente, a turma não reagiu fora da normalidade. Foi observado que quando a sala ficava barulhenta o aluno A ficava agitado e colocava as mãos nos ouvidos, quando a professora falava alto também o aluno A se agitava, demonstrando o seu desconforto com relação ao barulho. A professora percebeu, baixou a voz e o Aluno A sorriu (isso foi uma reação). Diante dessas observações, seria interessante rever algumas práticas de sala? O que poderia mudar? Sugerimos uma "Roda de conversa", com os profissionais envolvidos neste trabalho, que ficou agendada para o segundo semestre de 2017. Após planejarmos o que é possível ser feito para melhorar as práticas inclusivas nesta sala de aula, faremos um projeto de ação para desenvolver em conjunto com os professores, mediadores e a coordenação pedagógica nessas salas que tem alunos com TEA.

Com relação às entrevistas realizadas com as professoras sobre as principais dificuldades pedagógicas: a professora P1 declarou que: “A nossa maior dificuldade é a adaptação das atividades, mas estamos fazendo o possível, pois o livro vem igual para todos e nós precisamos adaptar tudo, isso dificulta muito".

A professora P2 completou dizendo que: "Acredito que se a Editora ${ }^{14}$ desse um treinamento para adaptações das atividades para os alunos com TEA, principalmente para Língua Estrangeira, facilitava muito.” A professora P1, disse que trabalha também com projeto, dividindo as atividades para a sala e para casa.

A professora P1 ainda falando das dificuldades, tocou num assunto importante que é a aprendizagem:

Outra grande dificuldade que vejo é com relação à comunicação: Às vezes ficamos com dúvida se o aluno $M$ aprendeu ou não, pois além da falta de comunicação, porque ele não utiliza a fala, então ficamos sem entender quais as dificuldades dele em aprender determinado assunto. As atividades adaptadas ajudam à essa compreensão, mas de forma parcial, pois a mediadora como direciona a realização das atividades do aluno A, ficamos sem um retorno por parte do aluno. Isso é crucial para nós. Mas, já houve avanços com relação a isso, porém não é suficiente. Acredito que é um aprendizado constante, com relação à essas práticas pedagógicas (PROFESSORA P1, 2017).

A fala da professora P1 reforça o que os teóricos já relataram e que expusemos anteriormente neste trabalho: a dificuldade de comunicação dificulta a tomada de decisão e a aprendizagem do aluno com TEA.

${ }^{14}$ Ao falar na Editora, a professora se referiu a Editora dos livros didáticos adotados pela escola, para o respectivo ano letivo. 
Ao perguntar à mediadora $\mathrm{M}$ sobre as dificuldades, esta declarou que a maior delas é a adaptação das atividades, pois às vezes não se sabe como adaptar e não tem uma explicação pedagógica de como fazê-lo. M relatou também que sexta-feira é realizado o planejamento de todas as atividades adaptadas para a semana e que não tem dificuldade para que o aluno A realize as tarefas. No entanto percebemos que pode existir alguma dificuldade não relatada na sua fala. $M$ foi questionada sobre a percepção de avanços no aluno e ela respondeu: "Avançou, tanto na aprendizagem como na questão do comportamento". Outra dificuldade que a mediadora M relatou foi com relação ao intervalo, pois não conseguiu levar o aluno A para participar da hora do "recreio" de forma satisfatória. A mediadora $\mathrm{M}$ afirmou que usa o método ABA, rotina à adaptação de atividades. Em conversa informal com a mãe do aluno $\mathrm{A}$, tivemos informação que o PECS está sendo introduzido aos poucos na sua rotina.

Ao perguntar à coordenadora pedagógica sobre as principais dificuldades, ela declarou:

A falta da fala eu considero um obstáculo, mas temos procurado fazer o melhor para entender o que ele quer e a falta de interação também é outro obstáculo. E uma grande dificuldade é a adaptação das atividades e trabalhar com o currículo, porque não trabalhamos apenas com um tipo de deficiência, mas com várias, depende da demanda (CP, 2017).

Podemos perceber a preocupação da coordenadora é pertinente em relação ao currículo e a adaptação das atividades, porém a dificuldade de comunicação do aluno A, com relação à fala permeia todos os depoimentos. É importante ressaltar que a família tem dado contribuições relevantes para o sucesso do tratamento e do processo educativo do aluno A. Isso é visível pelas ações da família, citando para ilustrar - a criação da AMA - Cariri, que foi iniciativa da própria família do aluno A. Todas as entrevistadas sugeriram cursos de capacitação para melhorar a prática pedagógica de sala de aula e metodologias para a adaptação de atividades e aprofundamentos nos métodos que ajudam a lidar e ensinar a alunos com TEA.

\section{Considerações finais}

Podemos concluir de forma parcial, já que esse trabalho é um passo inicial de uma pesquisa que está em andamento e que não é fácil para o professor dominar de forma eficiente práticas pedagógicas que não foram estudadas na sua formação inicial. Vale reforçar que muitos professores estão nas salas de aulas que tem alunos com TEA

RPGE- Revista on line de Política e Gestão Educacional, Araraquara, v.21, n. esp.2, p. 1031-1047, nov. 2017.2 ISSN: 1519-9029 
e não sabem lidar com essa situação e muitos mediadores, não fazem de forma eficiente o papel de mediador da aprendizagem, por falta de conhecimento e formação adequada.

É necessário atenção e investimentos direcionados para classe docente para efetivar uma formação voltada para as diferenças e práticas inclusivas. Se o corpo docente da escola não tem essa formação, a sugestão mais coerente é ofertar essa formação continuada, mesmo de curta duração. Outra sugestão é a formação de grupo de estudos vinculados às Universidades da região e rodas de conversas para ouvir os sujeitos envolvidos no processo educativo inclusivo. Buscar ajuda nas Instituições municipais (Secretaria Municipal de Educação), também poderá colaborar na solução de alguns pontos negativos detectados.

A escola como lócus do processo educativo, deve proporcionar um diálogo saudável, mesmo com os prós e contras de suas ações que nem sempre respondem às expectativas das famílias. O professor como um dos protagonistas desse processo na luta diária não deve ficar omisso, mas relatar as suas dificuldades na busca de soluções, mesmo consciente desse sistema fragilizado, que exige muito do profissional da educação.

Não é mágica que faz o professor dominar as técnicas pedagógicas, mas uma dedicação diária, estudo, planejamento, vontade de mudar e cursos de formação continuada, que lhe darão suporte para refazer o caminho de sua prática docente. Ação, reflexão e ação no dizer de Freire (1996).

Escola e família juntas têm atribuições imprescindíveis no processo educativo da criança com autismo, sem os pais essa luta se torna ainda mais difícil.

Os sujeitos entrevistados revelaram nas suas falas que apesar de utilizarem os métodos ABA (análise Aplicada do Comportamento) e PECS (Sistema de Comunicação pela troca de figuras) como práticas pedagógicas eficientes, ainda sentem muitas dificuldades com relação à adaptação de atividades (exercícios, trabalhos individuais e coletivos) e explicação dos conteúdos programáticos curriculares, como também a comunicação com os alunos autistas e a falta de formações continuadas para a efetivação das práticas inclusivas na escola, sendo esta última decisiva para a busca de conhecimentos capazes de provocar novas discussões e novas possibilidades didáticas.

Foi sugerido de forma enfática, cursos de capacitação, mesmo de curta duração, para melhorar a prática pedagógica de sala de aula e as metodologias para a adaptação de atividades, bem como aprofundamentos nos novos métodos e projetos que ajudam a lidar e ensinar os alunos com TEA. 
Esclarecemos que esses resultados parciais serão discutidos na escola e no Grupo de Estudos (Inclusão e os desafios na educação - da Universidade Regional do Cariri - Campus Missão Velha). Os relatos das entrevistas serão ampliados em trabalhos posteriores, bem como as observações que continuarão sendo realizadas no decorrer deste ano para planejamentos de novas práticas, com o objetivo de melhorar o processo de ensino-aprendizagem.

\section{REFERÊNCIAS}

BELISÁRIO FILHO, J. F.; CUNHA, P. A educação especial na perspectiva da inclusão escolar: transtornos globais de desenvolvimento. Brasília: Ministério da Educação. Secretaria de Educação Especial. 2010.

BRASIL. Constituição da República Federativa do Brasil. São Paulo: Atlas, 1988.

BRASIL. Declaração de Salamanca e Linhas de Ação sobre Necessidades Educativas Especiais. Brasília: Coordenadoria Nacional para Integração das pessoas portadoras de Deficiência, 1994.

BRASIL. Lei de Diretrizes e Bases da Educação Nacional. Lei n 9394, de 20 de dezembro de 1996. D.O.U., dezembro de 1996, Brasília, 1996.

BRASIL. Lei Berenice Piana. Institui a Política Nacional de Proteção aos Direitos da Pessoa com Transtorno do Espectro Autista. Lei 12.764/2012, de 27 de dezembro de 2012.

BRASIL. Ministério da Educação. Secretaria de Educação Especial. Documento subsidiário à política de inclusão. Brasília: SEESP, 2007.

CUNHA, E. Autismo na escola: Um jeito diferente de aprender, um jeito diferente de ensinar. Rio de Janeiro, Wak editora, 2013.

CUNHA, E. Autismo e inclusão: psicopedagogia e práticas educativas na escola e na família. Rio de Janeiro, WAK Editora, 2011.

FACION, J. R. Inclusão escolar e suas implicações. 2 ed. Curitiba: IBPEX, 2008.

FREIRE, P. Pedagogia da autonomia: saberes necessários à prática educativa. São Paulo: Paz e terra, 1996.

MACÊDO, C. R. S. de. A criança com Transtorno do Espectro Autista (TEA) e o professor: uma proposta de intervenção baseada na experiência de aprendizagem mediada (EAM).

Disponível em:

<https://repositorio.ufrn.br/jspui/bitstream/123456789/20038/1/ClaudiaRobertoSoaresD eMacedo_DISSERT.pdf>. Acesso em: 18 jul. 2017.

RPGE- Revista on line de Política e Gestão Educacional, Araraquara, v.21, n. esp.2, p. 1031-1047, nov. 2017. $\quad$ ISSN: 1519-9029 
MANTOAN, M. T. E. Inclusão escolar: o que é? por quê? como fazer? São Paulo: Moderna, 2003.

PEREIRA, A. C. dos S. et al. Transtorno do Espectro Autista: definição, características e atendimento educacional. Educação Revista Batatais, v 5, nº 2. p 191-212, 2015.

POULON, S. M.; FREITAS, L. B. de L.a; PINHO, G. S. Documento Subsidiário à política de Inclusão. Ministério da Educação. Secretária de educação Especial. Brasília, 2005.

Disponível em:

<http://portal.mec.gov.br/seesp/arquivos/pdf/docsubsidiariopoliticadeinclusao.pdf > Acesso em: 15 jul. 2016

RODRIGUES, J. M. C.; SPENCER, E. A criança autista: um estudo psicopedagógico. Rio de Janeiro, Wak editora, 2010.

VIEIRA, S. C. P. Os benefícios do PECS. Revista Autismo, 3 ed., ano 4, mar. 2013.

\section{Como referenciar este artigo}

MAGAlHÃES, Célia de Jesus Silva et al. Práticas inclusivas de alunos com tea: principais dificuldades na voz do professor e mediador. Revista on line de Política e Gestão Educacional, Araraquara, v. 21, n. esp. 02, p. 1031-1047, nov. 2017. Disponível em: <http://dx.doi.org/10.22633/rpge.v21.n.esp2.2017.10386>. E-ISSN: 1519-9029.

Submetido em: 09/09/2017

Aprovado em: 21/09/2017 